\title{
ENCONTRO ENTRE POLÍTICA DE QUALIFICAÇÃO E TRAJETÓRIAS
}

\section{SOCIAIS}

Maria Virginia Righetti Fernandes Camilo ${ }^{1}$

\section{RESUMO}

Este trabalho analisa o processo de implantação e expansão do Programa de Aprimoramento em Serviço Social da UNICAMP-Campinas em dupla dimensão: sua inscrição no Programa do Estado de São Paulo relacionada à política de saúde brasileira e experiências das alunas profissionais que o realizaram, com inserção no mercado de trabalho. O recorte espaço/tempo definiu-se pelo Aprimoramento em Serviço Social realizado no Hospital de Clínicas da UNICAMP no período de 1994/2001, implantação e estabilização de cursos/ bolsas. Trata-se de um estudo quanti-qualitativo, utilizando fontes documentais, bibliográficas, questionários ao universo total de alunos, privilegiando trajetórias sociais através de fonte oral, com depoimentos.

PALAVRAS-CHAVE: Qualificação; Saúde; Serviço Social.

\section{INTRODUÇÂO}

A relevância do estudo relaciona-se ao fato de qualificar para a saúde o profissional de Serviço Social, cuja demanda é pulverizada em vários campos, sendo que no Estado de São Paulo 38\% dos profissionais inseridos no mercado de trabalho estão na saúde (CRESS, 2004). A categoria participa mais efetivamente dos Congressos de Saúde Coletiva, promovido pela Associação Brasileira de Saúde Coletiva ABRASCO, sendo que em 2000 foi a terceira categoria com maior número de representantes presentes. No Estado de São Paulo as universidades públicas paulistas USP, UNESP e UNICAMP, têm organizado desde 1997 Congressos para assistentes sociais na saúde, sendo o último realizado em abril de 2006.

\footnotetext{
${ }^{1}$ Doutora em Educação pela UNICAMP, Assistente Social do Hospital de Clínicas da UNICAMP e Docente do Curso de Serviço Social do ISCA Faculdades Limeira.

\begin{tabular}{llllll}
\hline Serviço Social \& Saúde & Campinas & v. 6 & n. 6 & p. $1-170$ & Maio 2007
\end{tabular}
}


A Associação Brasileira de Ensino e Pesquisa em Serviço Social - ABEPSS realizou em setembro de 2006, em São Paulo, Oficinas Regionais que discutiram a formação para saúde inclusa na avaliação da implantação das diretrizes curriculares e do projeto ético político, ao que este estudo poderá contribuir.

A preocupação em formar profissionais que possam atuar frente à política pública de saúde resultou na publicação "Serviço Social e Saúde: formação e trabalho profissional", com um conjunto de temas relevantes abrangendo a política de seguridade, a saúde, o controle social, a relação particular entre o Projeto Ético Político e a Reforma Sanitária e os desafios colocados à profisssão em sua inserção nas equipes interdisciplinares em que o social perpassa todo o trabalho em saúde. ${ }^{2}$

As questões que nortearam essa pesquisa foram: Por que o estado de São Paulo cria e expande o programa de qualificação profissional para a saúde pública num contexto de modificações de seu papel, ampliando atuação para implementação de políticas de mercado? Quem são os sujeitos que buscam essa forma de qualificação? Quais os motivos que direcionam essa demanda ao Programa de Aprimoramento Profissional-PAP em Serviço Social? De que formas se inserem no mercado de trabalho num contexto de desemprego e precarização das relações de trabalho?

A hipótese norteadora do estudo é que o PAP em Serviço Social expande-se nos anos 90, a partir da crescente absorção destes profissionais na área da saúde, em função do modelo assistencial implantado através do Sistema Único de Saúde - SUS. O PAP significa uma possibilidade a mais de escolarização e qualificação, sobretudo para alunos oriundos de grupos sociais de baixa renda, possibilitando para muitos, ascensão profissional e social. A idéia hegemônica presente no mercado de trabalho tende a

2 Trata-se da publicação recente: MOTA, A. E., et al (Orgs). Serviço Social e Saúde. Formação e Trabalho Profissional, lançado no X ENPESS - Encontro Nacional de Pesquisadores em Serviço Social ocorrido em dezembro de 2006 em Recife.

\begin{tabular}{llllll}
\hline Serviço Social \& Saúde & Campinas & v. 6 & n. 6 & p. $1-170$ & Maio 2007
\end{tabular}


colocar para o indivíduo toda a responsabilidade pelo sucesso ou fracasso frente à qualificação profissional, geralmente deixando de lado as relações sociais que estruturam a sociedade, num processo contínuo que privilegia a acumulação do capital em detrimento da distribuição da renda e redução das desigualdades.

Hoje não basta a conclusão de um curso superior, mas a busca contínua e incessante por atualizações e qualificação para o trabalho. Nessa perspectiva, a educação superior tem ampliado a oferta de cursos em pós-graduação lato sensu para todas as áreas profissionais. E aqui a educação torna-se questão central, pois não responde apenas pela formação escolar, mas também pela qualificação profissional. Com o aumento do desemprego estrutural, a cada dia são exigidos mais requisitos para ocupação de postos de trabalho. Para Antunes (2002) a qualificação é exigida dos trabalhadores, com freqüente pressão para cursos de atualização e, mesmo assim, sem garantia de emprego.

O conceito de qualificação para o trabalho referenciado neste estudo privilegia a sua análise como relação social:

Uma relação social (de classe, de gênero, de etnia, geracional) que se estabelece nos processos produtivos, no interior de uma sociedade regida pelo valor de troca e fortemente marcada por valores culturais que possibilitam a construção de preconceitos e desigualdades Isso quer dizer que os conhecimentos adquiridos pelo trabalhador através de diferentes processos e instituições sociais - família, escola, empresas, etc - somadas as suas habilidades, também adquiridas socialmente, acrescidas de suas características pessoais e subjetividade, de sua visão de mundo que constituem um conjunto de saberes e habilidades que significa, para ele, trabalhador, valor de uso. Este só se transforma em valor de troca, em um determinado momento histórico, se reconhecido pelo capital como sendo relevante para o processo produtivo (SEGNINI, 2000, p. 20) 


\section{O PAP - PROPOSTA DE QUALIFICAÇÃO PARA A SAÚDE PÚBLICA}

A compreensão acerca das origens do Programa de Aprimoramento Profissional $^{3}$, enquanto política pública de qualificação para saúde, iniciativa exclusiva do Estado de São Paulo, conduz à retrospectiva histórica da política de saúde no Brasil, com seus embates e disputas entre modelos assistenciais.

O momento de inflexão que marca a mudança de concepção de saúde e de modelo assistencial ocorre nos anos 80 , quando o país passa por um processo de luta pela redemocratização após longo período ditatorial que não encontrava mais base de sustentação face à pressão e organização da sociedade civil. Dentre as demandas sociais e políticas, a saúde elabora um projeto a partir de um grupo de profissionais da área e de segmentos organizados, a Reforma Sanitária. Esta prevê a regulação política via Estado, considerando-a um direito de cidadania, pautado na compreensão social do processo saúde/ doença em que estão presentes as condições de vida, trabalho, moradia, alimentação.

Trata-se de uma política que se inscreve num projeto socializado para a saúde, "desmercadorizado"4 conforme refere Esping-Andersen.(1991) Portanto, esse modelo contraria interesses do grupo que defende um modelo assistencial regulado com a presença mínima do Estado, deixando ao mercado a regulamentação do acesso aos serviços, ou seja da saúde privada, ligada aos planos e seguros saúde e à medicina liberal.

\footnotetext{
${ }^{3}$ Programa de Bolsas para Aprimoramento de Médicos e outros profissionais de Nível Superior que atuam na Saúde, foi criado pelo Decreto Estadual 13.919 de 11 de setembro de 1979, ampliado pelo Conselho Estadual de Formação Profissional da Área da Saúde-CONFORPAS, Decreto n²8.495 de 15/06/1988. Trata-se de curso com um ano de duração, com 1980 horas, em que o aluno tem 20\% de teoria e $80 \%$ de prática e recebe bolsa.

${ }^{4}$ A palavra desmercadorização não foi encontrada no dicionário da língua portuguesa, mas foi encontrada no texto do autor Esping Andersen traduzida por Dinah de Abreu Azevedo na Revista Lua Nova n 24 de setembro de 1991.

$\begin{array}{llllll}\text { Serviço Social \& Saúde } & \text { Campinas } & \text { v. } 6 & \text { n. } 6 & \text { p. } 1-170 & \text { Maio } 2007\end{array}$
}


A Reforma Sanitária prevê novo modelo assistencial, de acesso universal, não discriminatório, hierarquizado conforme os níveis de complexidade de atenção e serviços, contendo cobertura básica a toda população, para responder aos problemas de menor complexidade em caráter preventivo e terapêutico, privilegiando o território a esfera local, a partir de indicadores epidemiológicos.

Sua proposta é tornar a saúde uma política pública inscrita na proteção social de caráter universalista, pautada no princípio do direito do cidadão e de dever do Estado, em que o usuário teria assegurado o direito não dependendo do mercado, a não ser que fosse sua preferência ou escolha. O modelo assistencial da Reforma Sanitária recusa a inscrição da saúde na lógica mercantil, pois seu ideário pauta-se no projeto de "defesa da vida" conforme refere Campos" (2003).

A origem do Programa de Aprimoramento Profissional-PAP se inscreve no início dos anos 80, na tentativa de unificar as propostas públicas de qualificação profissional para a saúde no Estado de São Paulo. Entretanto, é a partir de 1988, com a essência do projeto da Reforma Sanitária adquirindo o estatuto legal, que o PAP se amplia de maneira significativa, criando o Conselho Estadual da Formação Profissional na Área da Saúde-CONFORPAS, assumindo a responsabilidade de formação profissional para a saúde, agora não mais centrada apenas na residência médica, mas em outros profissionais de saúde, principalmente com ações multi e interdisciplinares.

Essa inflexão do PAP ocorre pela evolução do sistema de saúde que universaliza o acesso a serviços, pela adoção do princípio de atenção integral, bem como pelos avanços científicos e tecnológicos que incorpora diversos saberes profissionais. As

\footnotetext{
${ }^{5}$ Campos é considerado um dos expressivos intelectuais da Reforma Sanitária. Foi Secretário Municipal da Saúde de Campinas por duas vezes e ocupou cargo de secretário executivo do Ministro da Saúde no Governo Lula. Afastou-se do Ministério ao final de 2004.

\begin{tabular}{llllll}
\hline Serviço Social \& Saúde & Campinas & v. 6 & n. 6 & p. 1-170 & Maio 2007
\end{tabular}
}


profissões de saúde passam a qualificar-se para responder a um modelo assistencial pautado no princípio organizacional do Estado, de caráter público.

Entretanto, a implementação do SUS ocorre no momento em que o país, ao voltar-se à democracia política com eleições diretas, dá uma guinada em seus propósitos, pressionado pelas instâncias de monitoramento externo de poder global como o Banco Mundial, Banco Interamericano de Desenvolvimento - BID, voltando-se ao modelo que privilegia o mercado na regulação das relações sociais. O Estado se faz presente, para tornar legítima essa proposta, com a redução de suas atribuições a partir do discurso de excesso de burocratização e ineficiência operativa.

Toda essa mudança que ocorre mundialmente vem acompanhada de inovações tecnológicas e de interferências de novos processos produtivos que repercutem no mercado de trabalho com aumento de desemprego, flexibilização, com trabalho de curta duração, tempo parcial, sub-contratação, diminuição de salário, da exigência de qualificação para manutenção do emprego.

Como viabilizar uma política pública de saúde num contexto caracterizado pela ênfase nas soluções de problemas sociais via mercado, minimizando o histórico papel do Estado?

O estudo aponta que justamente nesse período controverso e permeado de disputas políticas, o PAP expande-se na área de Serviço Social, praticamente dobrando o número de cursos ofertados. Portanto o PAP se amplia nos anos 90 quando justamente o modelo político hegemônico nos países mais desenvolvidos é o de retração dos direitos sociais, do modelo de proteção social. Os dados da FUNDAP (2003) confirmam a expansão do mercado de trabalho em saúde no Estado de São Paulo nos anos 90, apontando, índice de crescimento maior para os profissionais não-médicos.

\begin{tabular}{llllll}
\hline Serviço Social \& Saúde & Campinas & v. 6 & n. 6 & p. $1-170$ & Maio 2007
\end{tabular}


Nessa disputa de modelos assistenciais, ocorre o que Giovanella (1996) refere como reordenamento do setor saúde. A universalização da atenção pelo Estado não se fez acompanhar de investimentos necessários, sendo que o SUS atende $73 \%$ da população brasileira. Isso mostra que $27 \%$ da população utilizam os serviços privados de planos e seguros saúde. (BRAGA; BARROS SILVA, 2001)

A política de saúde no Brasil se move num terreno de instabilidade, em que transitam os serviços pautados por princípios constitucionais de avanços consideráveis, sendo a única política pública da seguridade social brasileira de caráter universal, mas com dificuldades concretas de custeio e manutenção, devido aos insuficientes investimentos na área social que interferem diretamente nas condições de saúde da população, seguindo o monitoramento de agentes externos como o FMI, ajustando gastos e diminuindo investimentos.

Esses dados são confirmados comparando-se o período de 1993 a 1999, estudo de Piola \& Biasoto Junior (2001) em que se considerando o valor de 1999 corrigido a despesa foi 4,2\% inferior aos anos de 1997 e 1998.

Pelo exposto, há uma tensão permanente em torno de duas propostas de modelos assistenciais em saúde; a proposta da Reforma Sanitária responsabilizando o Estado pela regulação dos serviços, com caráter público, de direito de cidadania e outra que acompanha as disputas na área, o modelo privativista que propõe ao Estado os cuidados mínimos em saúde e a grande rede assistencial para o mercado.

O mercado é regulado pelo capital, ou seja, através de seguradoras, dos planos de saúde, que impões restrições aos usuários, quer em termos de número de consultas, serviços e procedimentos, como de cobertura a doenças pré-existentes.

A pesquisa registra o aumento da presença do profissional de Serviço Social na área da saúde, sendo que a ampliação da oferta de cursos no PAP/

\begin{tabular}{llllll}
\hline Serviço Social \& Saúde & Campinas & v. 6 & n. 6 & p. $1-170$ & Maio 2007
\end{tabular}


FCM/UNICAMP, nos anos 90, de 3 para 18 cursos, reitera o dado. Ou seja, o assistente social torna-se alvo da proposta de qualificação profissional para o setor público de saúde, muito embora sua presença na área se remonte à década de 40 , nas origens da profissão no Brasil.

Dados recentes do CRESS São Paulo (2004) confirmam que a saúde hoje absorve em torno de $38 \%$ dos profissionais inseridos no mercado de trabalho, respondendo por mais de um terço dessa demanda. Todos esses elementos de certa forma pressionaram a representação coletiva dos profissionais. Em 1999 o Conselho Federal de Serviço Social - CFESS, através do decreto n³83/99, reconhece o assistente social como profissional da saúde.

Nesse controverso movimento, se inscreve os Cursos de Aprimoramento em Serviço Social como política pública de qualificação para o trabalho em saúde na interconexão das relações entre educação, trabalho e saúde. Educação por ser uma pósgraduação lato sensu, voltada à qualificação para a saúde pública, num modelo político que privilegia o mercado, e, no mercado de trabalho em que ocorrem modificações na oferta e nas relações de trabalho.

Os Cursos de Aprimoramento em Serviço Social crescem nos anos 90, resultante, de um lado, da expansão do cuidado em saúde para outros profissionais, e, de outro, da implementação do SUS, privilegiando o município, a esfera local para o desenvolvimento dos projetos e das ações em saúde, o que repercutiu na demanda por estes profissionais.

\section{CONSIDERAÇÕES FINAIS}

Os resultados dessa pesquisa corroboram a hipótese de que a expansão do PAP nos anos 90 ocorre a partir da crescente absorção destes profissionais na área da saúde

\begin{tabular}{llllll}
\hline Serviço Social \& Saúde & Campinas & v. 6 & n. 6 & p. $1-170$ & Maio 2007
\end{tabular}


em função da implementação do SUS. A contribuição do estudo não se restringe à análise do PAP como política pública de qualificação para saúde, mas o encontro entre política pública e sujeitos. O estudo aponta para a dimensão histórica dos sujeitos que vivenciaram o processo de qualificação do PAP em Serviço Social no Hospital de Clínicas da UNICAMP, no período de 1994 a 2001.

Nesse sentido, a opção pelo referencial teórico de Thompson (1981) contempla a história como processo, resultante de escolhas e lutas humanas, de sujeitos que se constroem nesse movimento. Através das trajetórias, as relações de classe, gênero, geracional, presentes no processo de socialização na esfera familiar, escolar, expressam o lugar social, em que ocorreram as experiências, não como histórias pessoais mas principalmente como coletivos sociais em que se inserem.

A comparação entre origem social e posição atual (BERTAUX, 1979) das entrevistadas permite inferir que as alunas do PAP pertencem a segmentos sociais que buscam o ensino superior e uma profissão através de cursos noturnos em rede privada de ensino, pois trabalhavam e não tiveram acesso ao ensino público. Alunas com pais mais escolarizados e profissão de nível superior percorrem trajetória diferente, com estudo na rede privada e acesso à universidade pública, com outras expectativas na infância e adolescência.

A fonte oral possibilitou a qualificação das trajetórias sociais, num contexto histórico dos sujeitos que, ao expressarem suas informações, apontaram as formas de lutar, enfrentar situações adversas, de utilizar estratégias de resistência, de oposição à condição de exploração, de vivência da pobreza.

A origem familiar das entrevistadas tem eixo comum: o trabalho assalariado dos pais seja na cidade grande como nas mais distantes, a migração, a pobreza, que leva crianças e adolescentes ao trabalho precoce, num uso do tempo voltado apenas à \begin{tabular}{llllll}
\hline Serviço Social \& Saúde & Campinas & v. 6 & n. 6 & p. $1-170$ & Maio 2007
\end{tabular} 
sobrevivência, sem dispor do tempo para o lazer, para a fruição. Essa experiência desenvolve a consciência de classe, do lugar que ocupam na sociedade, provocando uma diversidade de estratégias de recusa à situação, de resistência e enfrentamento.

Os elementos que marcam profundamente as trajetórias sociais das entrevistadas se inscrevem nas diferentes estratégias de resistência, de não aceitar a pobreza como condição "natural", mas de se opor a ela, de recusar os trabalhos oferecidos, de buscar outras formas de inserção que possibilitassem sair da situação, de colocar a educação como um valor a ser perseguido, conquistado, de identificar-se com os coletivos via movimentos sociais.

Colocando a educação como valor, experimentam o processo de desigualdade de oportunidades, estudando em escolas públicas no ensino fundamental e médio, mas tendo que, muitas vezes, combinar estratégias de educação e trabalho infantil, buscando na escolha da profissão uma oportunidade de mobilidade social ascendente.

A escolha profissional recai sobre uma opção eminentemente feminina, que desde sua origem, insere-se nas ocupações cujo universo é basicamente de mulheres. Dados recentes confirmam a feminização, sendo a terceira ocupação com maior contingente de mulheres (FUNDAÇÃO CARLOS CHAGAS, 2004). Está relacionada ainda a experiência social das trajetórias, de visualizar na profissão um aporte aos direitos e a justiça social, e ao mesmo tempo observar experiências profissionais de maneira próxima nos serviços.

São mulheres que enfrentam as adversidades de situações de relações sociais hierarquizadas, buscando profissionalização ao concluir o ensino médio quando jovem, ou mesmo, mais tardiamente quando já casadas, com filhos. De forma semelhante as grandes parcelas de jovens trabalhadores brasileiros, tiveram acesso ao ensino superior via setor privado, custeando os próprios estudos, pois a educação superior não é direito.

Serviço Social \& Saúde Campinas $\quad$ v. 6 n. 6 p. 1-170 $\quad$ Maio 2007


Embora o Estado de São Paulo tenha 24 cursos de Serviço Social, apenas um é público, da UNESP. As universidades públicas parecem voltar as costas a essa demanda (CAMILO, 2005).

O PAP em Serviço Social na UNICAMP emerge na trajetória profissional das entrevistadas como forma de acesso ao ensino de nível superior público, de serem reconhecidas socialmente, pois a universidade ocupa posição de destaque na formação profissional, no desenvolvimento da ciência e da tecnologia. Outro fator é que o PAP oferece bolsa para pós-graduação lato sensu, ao invés do aluno pagar novamente pelo curso.

Entretanto, o fato chama atenção para outro aspecto que merece ser aprofundado em outras pesquisas: em que medida esses cursos para qualificar profissionais também não se constituem em fonte de recrutamento de profissionais bem formadas e especializadas, mas de baixo custo, considerando-se o valor da bolsa?

A inserção profissional após a qualificação mostra que o curso prepara o aluno, pois embora não sejam absorvidos todos na saúde, disputam concursos públicos para outras áreas, bem como parcela significativa volta-se para o trabalho docente. As formas de inserção no mercado de trabalho não estão descoladas do contexto dos demais trabalhadores com formas de trabalho precarizado e desemprego. Transitam nesses fluxos até conquistarem melhores possibilidades através de concursos públicos, com maior estabilidade e possibilidades de direitos.

As trajetórias sociais apontaram para o fato de que o PAP significa ao mesmo tempo uma possibilidade a mais de escolarização e qualificação, sobretudo para alunos originários de grupos sociais de baixa renda. A inserção profissional após a qualificação possibilitou um status de trabalhador, com possibilidade de mobilidade social ascendente.

\begin{tabular}{llllll}
\hline Serviço Social \& Saúde & Campinas & v. 6 & n. 6 & p. $1-170$ & Maio 2007
\end{tabular}


Ao finalizar esse trabalho retorno ao seu início, apontando a intercessão entre política de qualificação e experiência, na expressão de mulheres que depositaram na educação a esperança de mobilidade social ascendente, que resistiram às formas de opressão, que elaboraram diferentes estratégias e formas de resistência como revolucionárias do cotidiano.

Numa sociedade, ainda marcada por profundas desigualdades sociais, organizada na lógica mercantil em que a cidadania ainda é apenas um aceno legal, as experiências expressas nas trajetórias sociais de colocar a educação como valor, confirmam que esta ainda é uma porta que não se fecha.

\begin{abstract}
This work analyses the implementation and expansion of the Social Work Improvement Program at UNICAMP - Campinas, face two different sides: its subscription on the State of Sao Paulo Program related to health politics and the experiments of professional students who carried it out, with job market insertion. The space/time extract was defined by the Improvement in Social Service fulfilled at Hospital de Clínicas of UNICAMP during 1994 - 2001, implementation and stabilization of courses / scholarship. It's all about a quanti-qualitative study, using documental sources, bibliographies, question forms to the total universe of students, aiming social evolvement through oral source, with statements.
\end{abstract}

KEYWORDS: Qualification; Health; Social Work.

\title{
REFERÊNCIAS BIBLIOGRÁFICAS
}

ANTUNES, Ricardo. Palestra proferida no Seminário dos Cursos de Aprimoramento de Profissionais da Saúde FUNDAP/SP- Memorial da América Latina, São Paulo, 2002.

$\begin{array}{llllll}\text { Serviço Social \& Saúde Campinas } & \text { v. } 6 & \text { n. } 6 & \text { p. } 1-170 & \text { Maio } 2007\end{array}$


ASSOCIAÇÃO BRASILEIRA DE ENSINO E PESQUISA EM SERVIÇO SOCIAL Unidades de Ensino. Disponível em www.abepss.ufsc.br acesso em 10 de novembro de 2004

BERTAUX, Daniel. Destinos pessoais e estrutura de classe. Rio de Janeiro: Zahar Editores, 1979, p. 9-36.

BRAGA, Jose Carlos de Souza e SILVA, Pedro Luis Barros. A mercantilização admissível e as políticas públicas inadiáveis: estrutura e dinâmica do setor saúde no Brasil. In NEGRI, B. DI GIOVANNI, G. (Org) Brasil: Radiografia da Saúde. Campinas, SP: UNICAMP. IE, 2001.

CAMILO, M. V. R. F. A trajetória do direito à saúde. In Revista Serviço Social \& Sociedade n59. São Paulo, Cortez Editora, 1999.

CAMILO, M. V. R. F. Programa de Aprimoramento profissional para saúde: qualificação de assistentes sociais. Tese de Doutorado Faculdade de Educação UNICAMP. Campinas, 2005

ESPING-ANDERSEN, G. As três economias políticas do welfare state. In: Lua NovaRevista de Cultura e Política No 24. São Paulo, 1991

FUNDAÇÃO CARLOS CHAGAS - Banco de dados sobre trabalho das Mulheres. Disponível in WWW.fcc.org.br Acesso on line em 12 de outubro de 2004.

CAMPOS, Gastão Wagner de Sousa. Desafios do SUS. Palestra proferida no II Seminário dos Cursos de Aprimoramento Profissional para Saúde. Faculdade de Ciências Médicas UNICAMP. Campinas, 2003.

CONSElHO REgiOnal De SERVIÇO SOCIAL. São Paulo Ação - Boletim Informativo abril/junho 2004.

FUNDAÇÃO DO DESENVOLVIMENTO ADMINISTRATIVO Força de trabalho de nível superior na área da saúde Estado de São Paulo: 1992 e 1999. São Paulo, 2003.

GIOVANELLA, L.; FLEURI, S. Universalidade da Atenção à saúde: Acesso como categoria de análise. In EIBENSCHUT, C. (Org.) Política de saúde: o público e o privado. Rio de Janeiro, Editora Fio Cruz, 1995.

PIOLA, S. F.; BIASOTO JUNIOR, G. Financiamento do SUS nos anos 90. In NEGRI, B. ; DI GIOVAnNI, G. (Org.) Brasil: Radiografia da Saúde. Campinas, SP. UNICAMP. IE, 2001.

\begin{tabular}{llllll}
\hline Serviço Social \& Saúde & Campinas & v. 6 & n. 6 & p. $1-170$ & Maio 2007
\end{tabular} 
SEGNINI, Liliana R. P. Constantes Recomeços: Homens e Mulheres em situação de desemprego. São Paulo, Fundação Carlos Chagas. 2000.

THOMPSON, Edward P. A miséria da teoria ou um planetário de erros. Uma crítica ao pensamento de Althusser. Rio de Janeiro ZAHAR EDITORES S.A, 1981 